\title{
Corynebacterium renale
}

National Cancer Institute

\section{Source}

National Cancer Institute. Corynebacterium renale. NCI Thesaurus. Code C86322.

A species of aerobic or facultatively anaerobic, Gram-positive, coryneform, pleomorphic bacilli assigned to the phylum Actinobacteria. This species is nonmotile, non-spore forming, catalase positive, urease positive, pyrazinamidase positive, does not reduce nitrate, indole negative, non-lipophilic, ferments glucose, does not produce hydrogen sulfide, and does not hydrolyze gelatin. C. renale is an opportunistic pathogen that causes ascending urinary infection, pyelonephritis and abscesses. 